\title{
HOW AND WHY PSYCHIATRISTS SHOULD USE IMAGING METHODS
}

\author{
Tomas Kasparek* \\ Department of Psychiatry, Masaryk University, Faculty of Medicine \\ \& Faculty Hospital Brno-Bohunice, Brno, \\ Czech Republic \\ Received June 1, 2010; accepted June 17, 2010
}

\begin{abstract}
From the perspective of a clinical psychiatrist, the extensive research in the field of imaging methods seems to have brought virtually no relevant information to practice (except for differential diagnoses of organic mental disorders). Mental disorders have not been shown to have a correlate detectable with common methods used in other branches of clinical medicine; neither do they provide access to subjective contents, i.e., they do not allow us to "read" our patients' thoughts or emotions, as popularized, particularly, by science fiction writers. However, imaging methods do have a significant role to play in psychiatry. Along with cognitive neuroscience findings, they allow us to understand the origin of certain psychopathological phenomena and formulate specific therapeutic approaches that can be used to influence them; together with findings from histopathology and animal studies, they allow us to assess the neuropathology of mental illnesses and assess the effectiveness of treatment modalities. Imaging techniques allow us to determine which parts of the brain are connected with a particular psychopathology, which in turn allows treatment selection to be focused on the anatomical and biological targets, linked to the psychopathology, thus offering benefits to the patient. Methods are beginning to appear which, using various brain imaging and multidimensional classification techniques, allow us (with increasing sensitivity and specificity) to determine which group an assessed subject belongs. This last feature is of greatest interest in clinical practice as it may be helpful with the diagnosis (i.e., whether the image of the brain corresponds to the healthy population or the suspected disorder) or in prediction (e.g. based on response to treatment, what are the probable courses for the illness, etc.). Thus, although mental illnesses are not accompanied by specific changes in the brain perceptible to the naked eye, if we ask clinically relevant questions, imaging methods provide us with important answers. This is why psychiatrists themselves should become knowledgeable and comfortable with imaging methods.
\end{abstract}

Key words: Neuroimaging; Neuropathology; Psychiatry; Schizophrenia

\section{INTRODUCTION}

What significance do imaging methods have for psychiatry? Modern high-resolution technologies, capable of imaging the structure as well as the function of the CNS, have been used for more than 20 years. They have brought considerable progress in neurosciences and related fields. But what have they contributed, and what are they likely to contribute, to psychiatry?

Let us start with two methods dreamed up by two greats from the world science fiction. In a sequel to his Foundation, Isaac Asimov describes an advanced EEG signal analysis technique which, besides remote recording, allowed assessment of the personality (character and temperamental) qualities together with the prediction of behavior in key situations. This idea reflects the concept that imaging methods can reveal complex and individually characteristic information. The question is whether we are able to recognize and make use of such information. Stanisław Lem, in his turn, imagined a method that could be used to record the contents of memory and to visualize it as a video recording. Let us ask, together with the writer, if imaging enables access

\footnotetext{
*Correspondence to: Tomas Kasparek, email: tomas.kasparek@centrum.cz
} 
to the contents of the "mind"? Such techniques would certainly be welcome by psychiatrists and psychologists, and even more so by investigators and judges; but, on the other hand, we should be rather afraid of them. Do current imaging methods allow for anything like that? That question will be dealt with in the following text.

What are we currently able to image? Using various methods based on the principle of magnetic resonance (MR) we are able to assess the morphology of the brain; not only its size, but also, for instance, the gyrification pattern and the local volume of grey matter (volumetry or computational neuroanatomy, e.g. voxel-based morphometry), while white matter integrity can be evaluated using a MRI method called diffusion tensor imaging. These approaches enable assessment of the brain structure with a resolution of just a few $\mathrm{mm}$. Using MR spectroscopy we can assess biochemical substances in the brain and, from the assessment, infer the viability of neurons (by means of $\mathrm{N}$-acetylaspartate levels), the state of energy metabolism (energy molecules), the state of cell membrane metabolism (phosphomono- and diesters), and levels of certain neurotransmitters (glutamate, GABA). Through the use of radioligands and methods of nuclear medicine (positron emission tomography (PET), single-photon emission tomography) we are able to assess the expression of neurotransmitter receptors, their interaction with administered drugs, etc. We are also able to assess brain function, or more precisely to study blood flow (fMRI) or glucose metabolism (PET) in particular areas of the brain during activation tasks. These methods enable us to monitor which areas of the brain are activated or deactivated when various tasks are being performed. We are, therefore, able to determine which brain areas are involved with which functions. Based on the pattern of activated areas, we can, for instance, estimate whether the subject employed executive functions or whether they performed an emotionally significant task (for review and examples of current neuroimaging methods see (Bandettini, 2009; Hurley and Taber, 2008). Yet we are not able to use them to evaluate the contents, i.e., what they were resolving, what they were imagining, or what they were thinking about. This kind of information is still accessible only via the clinical interview, which, of course, has many functions beyond the solely informative.

If we compare that which is offered by science fiction writers with current imaging potential, it seems that imaging methods can contribute very little or nothing to clinical practice. Indeed, clinical psychiatrists often argue that imaging provides information on theoretical issues that are remote from common practice. In clinical practice, imaging methods are mainly used for differential diagnosis of organic mental disorders (to differentiate between symptomatic disorders, "due to" disorders according to the American DSM-IV classification). Even with regard to this indication there remains skepticism about the efficiency of imaging in patients with psychiatric symptomatology (Lennox, 2009). Nevertheless, imaging studies have enabled psychiatry to make remarkable progress in understanding mental illnesses. In the following text, I am going to demonstrate, using some specific situations, ways in which we can make use of imaging methods in order to obtain clinically relevant answers to our clinical questions.

\section{Quantitative vs. qualitative assessment}

A great deal of misunderstanding concerning the significance of imaging methods in psychiatry stems from inadequate differentiation between qualitative and quantitative assessment of images. In clinical practice we use "qualitative" assessments, i.e. we look for qualitatively different characteristics in the image that have pathognomonic significance, for instance a shadow on a lung $\mathrm{X}$-ray or the occurrence of specific epileptiform graphoelements in an EEG. Unfortunately, such specific, pathognomonic qualitative changes are not found in mental disorders (Fenton, 1984).

Quantitative assessment, on the contrary, is based on statistical analysis of the parameters of the image used to detect changes and relationships not perceptible by the naked eye; for example bone densitometry used to detect places in the image of the skeleton in which the 2.5 standard deviation intensity is below the population standard (Vallarta-Ast et al., 2002). Quantitative assessment can allows us to test specific hypotheses, i.e., using imaging we can ask and answer clinically relevant psychiatric questions.

\section{Relationships between structure and function}

The conventional source of information about the relationship between CNS structures and their function are lesion studies (Rorden and Karnath, 2004). It is necessary to realize that the quality of information about this relationship depends on the quality of the description of the function, or rather its dysfunction (mental disorder). If the function is not adequately described, the relationship of the dysfunction / disorder to the localized brain lesion is misleading. There is an analogy here with imaging methods; therefore, if we wish to use imaging to study psychopathology and mental disorders, it is vital that psychiatrists themselves address this issue! 


\section{Levels of abstraction, imaging methods and psycho- pathology}

Before we focus on particular cases, we need to realize at what level of abstraction imaging methods work (Fig. 1). Any psychopathological process manifests itself at numerous levels, from genetic content, expression of genes and their regulation by epigenetic mechanisms, structure and function of proteins, subcellular structures and mechanisms, cells and cellular interactions, neurophysiological systems, mental functions, personality and partnership, to the individual's social environment. A primary pathology can develop at any of these levels. Through feedback mechanisms, adaptations and maladaptations then occur at the next levels, and, with regard to circular causality (effect influences causes and these changes in turn lead to changes in the effects) making it difficult to identify the cause and the effect of the adaptation (Beahrs, 1986). Therefore, the relationships between individual levels are sometimes very difficult to establish; nevertheless, the important fact remains that mental disorders can be understood as changes at many levels of abstraction and that it is possible to try to make use of this information in clinical practice, from diagnosis to therapy.

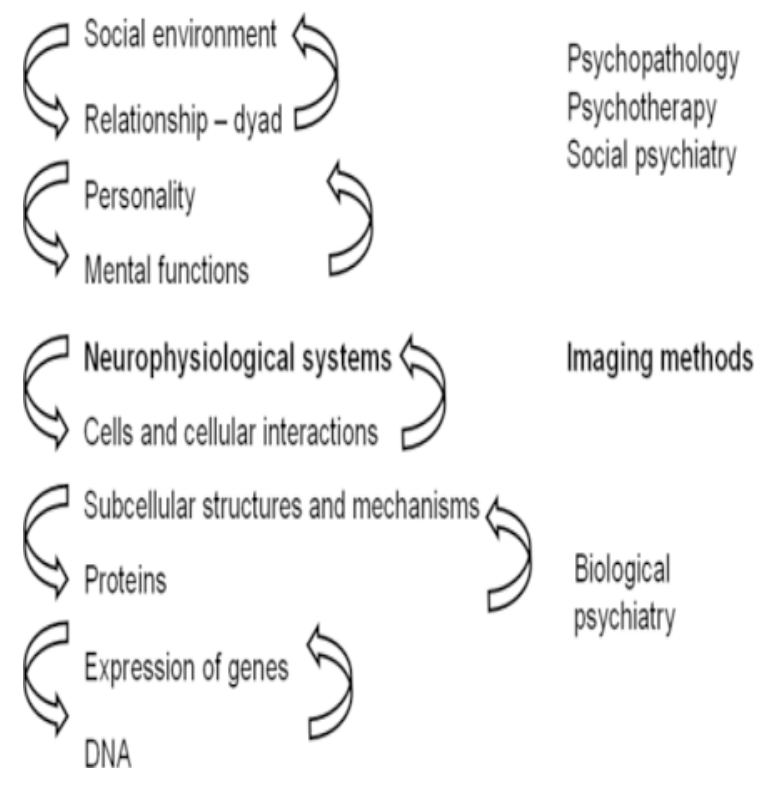

Figure 1. Levels of abstraction

The patient's personality is accessible via the clinical psychiatric interview, the contents of the patient's psyche are accessible through their references; relationship and social levels are also accessible. Psychopathol- ogy, psychotherapy and social psychiatry work at these levels. The methods of biological psychiatry can capture changes from the genome to the level of neurophysiological systems.

It is the level of neurophysiological systems that is accessible through imaging methods. In this respect, it is evident that imaging methods cannot constitute a single, universal approach that can fully explain all psychopathological phenomena. On the contrary, only by integrating information gained from different levels can the findings of imaging methods be understood in the context of the complex pathophysiology of a disorder and be correctly interpreted.

\section{APPLICATION OF IMAGING METHODS IN PSYCHIATRY}

We can now proceed to particular cases of using imaging methods in psychiatry; these cases demonstrate how the findings from imaging methods alter the understanding of an illness and of its pathophysiology; these cases also demonstrate the implications for diagnosis, case management and treatment.

\section{Computational tomography and neurobiology of schizophrenia}

In 1976, Johnstone published the first CT study involving schizophrenia (Johnstone et al., 1976). Using a CT brain scan she was able, in a group of chronically ill patients, to demonstrate the presence of enlarged lateral ventricles which, until then, had been a questionable finding of elder pneumoencephalographic studies. Later, it turned out that the enlargement of the ventricles was unrelated to medication or hospitalism (long-term hospitalization). This was a ground-breaking study and ever since schizophrenia has been regarded as an illness of the brain with a morphological and neuropathological correlate, and is not the functional illness it was once thought to be. These types of studies revived the interest in the neuropathology of schizophrenia, which, until that time, had been considered the "graveyard" of neuropathologists.

\section{Dopamine dysregulation in schizophrenia}

The "dopamine theory of schizophrenia" has been a leading theory since the 1960s. It is based on two basic postulates: 1) Dopamine D2 receptor blockade is the main mechanism of action of antipsychotics. This presumption is based on the key observation by Carlsson that neuroleptics increase catecholamine turnover 
(Carlsson and Lindqvist, 1963) and then on Seeman's finding of the relationship between the rate of attachment to D2 dopamine receptors and the clinically administered dose of various neuroleptics (Seeman et al., 1976). 2) Dopaminomimetics worsen (Angrist et al., 1980) or induce psychosis (Angrist et al., 1974). On the grounds of these observations, hyperfunction of the dopamine system in schizophrenia is presumed. However, direct evidence for this presumption was not available until recent studies were performed using methods of nuclear medicine - single-photon and positron emission tomography.

These studies focused primarily on the striatum, the target of the mesolimbic dopamine system. An increase in D2R density was found (Tune et al., 1993; Wong et al., 1986), i.e., there is an increase in the number of D2Rs, although not all studies were able to confirm these changes (Nordstrom et al., 1995). However, a meta-analysis of imaging methods did confirm the finding of the increase, the effect size of 1.47 bearing evidence of a relatively marked change (Zakzanis and Hansen, 1998). Changes in D1 receptor density were not found (Karlsson et al., 2002). Increased DOPA accumulation was found presynaptically (Hietala et al., 1995; Lindstrom et al., 1999; Reith et al., 1994), a finding compatible with increased dopamine synthesis. Changes in dopamine transporters were not found (Laruelle et al., 2000; Schmitt et al., 2005). This therefore means that changes in dopamine transmission are due to a functional disorder, not to a higher number of DA inputs into the striatum. Furthermore, higher D2 receptor availability was observed after dopamine depletion, i.e., basally, before depletion, more receptors are occupied by dopamine (or more precisely, more dopamine is present in the synapse (Abi-Dargham et al., 2000), and their hyperstimulation, increased DA transmission, is thus present. This is most likely an increase in phasic, i.e., stimulus-dependent dopamine release (AbiDargham et al., 2000). Increased dopamine response after amphetamine administration is also present (AbiDargham et al., 1998; Laruelle et al., 1996). On the other hand, a decrease in dopamine transmission is observed in the cortex which leads to the up-regulation of dopamine receptors (Abi-Dargham, 2003).

Thanks to PET and SPECT studies, we know that dopamine system dysregulation is present in schizophrenia. What does this signify and what are the clinical implications? In schizophrenia, we find hyperactivity of $\mathrm{D} 2 / 3$ receptors in the limbic system and, at the same time, hypoactivity of D1 receptors in the cortex. This happens because the mesolimbic and the mesocortical system are regulated in different ways. Both systems are under the influence of cortical glutamatergic neurons; the mesolimbic system of the ventral tegmental area indirectly, via GABAergic neurons. Since there exists hypofunction of the glutamate system in schizophrenia (Javitt, 2007), regulation of the dopamine system is insufficient, leading to inadequate function in the mesocortical area (the dopamine system being enhanced insufficiently) and to hyperactivity in the mesolimbic area (the dopamine system is held back insufficiently). This model is supported by the finding of increased DA transmission in nc. accumbens and its decrease in the prefrontal cortex after blockade of glutamate transmission in the ventral tegmental area (Takahata and Moghaddam, 2000). Decompensation of the dopamine system in schizophrenia occurs when stimuli activating the dopamine system, for instance stress (Kalivas and Duffy, 1995) or administration of amphetamine, are present. Feedback mechanisms are not capable of regulating the dopamine response.

Protracted mesolimbic hyperactivity subsequently leads to the development of psychosis. The mesolimbic dopamine system actually signals the meaning of the stimulus (Berridge and Robinson, 1998), i.e. which perceptions, thoughts, etc., are significant and which are not. This phenomenon is called "attribution of salience" and leads to the fact that we are able to select, from the volume of information with which we are constantly bombarded, with only elements that are behaviorally important, and thus avoid being flooded with perceptions. If the mesolimbic system is dysregulated, inadequate attribution of salience to neutral stimuli can occur. Delusions can then be understood as an explanation of abnormal salience, and hallucinations as abnormal salience of the internal representations mistaken for external perceptions (Kapur, 2003).

Why does D2 receptor blockade lead to an antipsychotic effect? Dysregulation of the dopamine system leads to incorrect attribution of salience which is reinforced by repetition, and psychosis develops. If we block D2 receptors, the abnormal attribution of salience is prevented, and the incorrect interpretations are gradually weakened, or more precisely new ones are created based on a correct attribution of salience (Kapur, 2003). Therefore, this model enables us to infer not only the mechanism of development of this psychopathological phenomenon, but also the mechanism of the acute antipsychotic effect, including its gradual onset. PET studies again show that the rate of $\mathrm{D} 2$ receptor occupancy in the striatum correlates with a decrease in positive schizophrenia symptoms, which supports the model 
described above (Agid et al., 2007). Dysregulation of the prophylactic use of antipsychotics - if the D2 receptor is blocked, mesolimbic hyperactivity is prevented and a psychotic relapse does not occur during stress situations (or other dopamine-stimulating situations such as abuse).

\section{In vivo imaging of neuropathology}

After morphological changes were found in schizophrenia, interest in the neuropathology of schizophrenia was revived. The key neuropathological change seems to be reduction in the thickness of the cortex, primarily of layers II and III. At the same time, a higher density of neurons, smaller sized pyramidal neuron cell bodies and a reduction in the dendritic tree size of these neurons, can be found in these layers. The pyramidal neurons of layers II and III integrate and transmit cortico-cortical connections (for a review see (Kasparek, 2009). It is also possible to assess the thickness of the cortex using magnetic resonance. Narr found that grey matter density and cortex thickness reflect similar parameters of brain morphology in schizophrenia (Narr et al., 2005). Thus, in schizophrenia, using voxel-based morphometry (VBM; it assesses the density or volume of grey matter in different voxels, parts of the brain), we can assess the bulk of the neuropil, i.e., connectivity rate. This means that VBM can be used for assessing the neuropathology of schizophrenia in vivo.

Honea carried out a systematic summary of results from 15 VBM studies in schizophrenia (Honea et al., 2005). Reduction in grey matter was found in virtually every cortical area; the studies agreed most often regarding changes in prefrontal and temporal areas. Even in these areas, however, there was considerable variability in localization of the changes. The changes in cortical grey matter, in schizophrenia, are, therefore, largely heterogeneous.

Findings of changes in grey matter are thus heterogeneous with regard to the spatial pattern of the affliction there may be neurobiological and hence clinical heterogeneity in the background. The differing rates of affliction of the individual structures manifest by functional differences in individual patients. We focused on these relationships and we found correlations between volume of the grey matter in the left gyrus temporalis superior, white matter in the left prefrontal cortex and performance on verbal fluency tests in patients with firstepisode schizophrenia (Kasparek et al., 2008). Similarly, we found relationships between grey matter concentration in the left putamen and the ability to sequence movements in first-episode schizophrenia patients the dopamine system also suggests and explanation for (Kasparek et al., 2009). Besides having functional consequences, morphological heterogeneity has significance relative to classification - see below.

Attempts at studying the effect of antipsychotics on brain morphology, using imaging, reveal the application limitations of these methods. Imaging studies suggest that there is a connection between taking antipsychotics and changes in morphology: first-generation APs lead to the enlargement of the basal ganglia in MRI images (Dazzan et al., 2005; Gur et al., 1998) and (perhaps) to a reduction in cortical grey matter (Dazzan et al., 2005; Lieberman et al., 2005). Second-generation APs cause regression of changes induced by APs I (Lang et al., 2004; Scheepers et al., 2001), (perhaps) a less pronounced progression of morphological changes in the total volume of grey matter (Lieberman et al., 2005; Thompson et al., 2008) and (perhaps) they lead to an increase in the volume of cortical grey matter (Garver et al., 2005; Molina et al., 2005). Nevertheless, can we argue, on the basis of these findings, that antipsychotics influence the basic neuropathology of schizophrenia? Animal histological studies assessing the effect of antipsychotics on the cytoarchitecture of the brain, showed that use of antipsychotics cause changes in the Vth and VIth layer of the cortex, their widening (for a review see (Kasparek, 2009). This widening may be interpreted, in MR images, as an increase in the volume of cortical grey matter; however, antipsychotics apparently do not intervene in the basic neuropathology of schizophrenia - perhaps, they only correct the dysfunction caused by the primary disorder, and the changes observed in MR images, therefore, do not show curative or neuroprotective effects, but only neuroplastic effects (Fig. 2). However, regarding the rather limited amount of information, primarily on the effect of newer substances, we can expect new findings which may correct these conclusions.

Besides the above mentioned, the findings of brain dissimilarities in schizophrenia, ascertained using VBM, have major and direct significance for day-to-day clinical practice: it is exactly because the findings underlie the level of subjective experience that it is possible (or rather, let us hope it soon will be) to communicate more easily with the patient about their illness. On a daily basis, at outpatient clinics and in hospital wards, we meet patients who do not accept the fact that they are mentally ill, or, to put it differently, do not regard the proofs of their illness, as acquired by our subjective assessment of their experience, thinking and behavior, as correct or meaningful. 


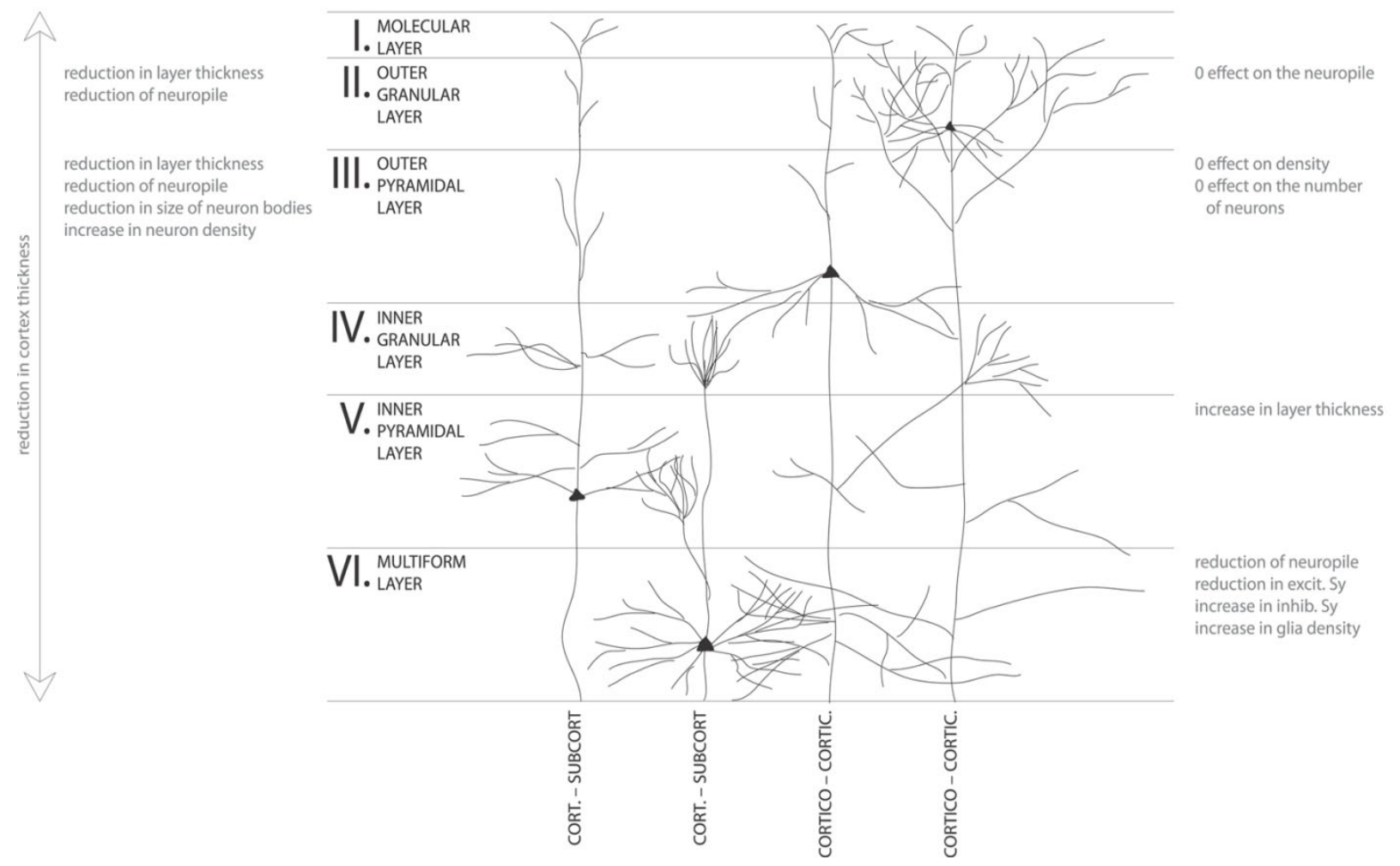

Figure 2. Neuropathology of schizophrenia and the effect of antipsychotics on cerebral cortex architecture.

The ability, or even the possibility, of assessing the unique features of an individual's psyche is questioned. If we could tell the patients that the diagnosis is supported by dissimilarity in the morphology or function of their brain, existing parallel to our subjective assessment, it might perhaps be easier to work with their anosognosia.

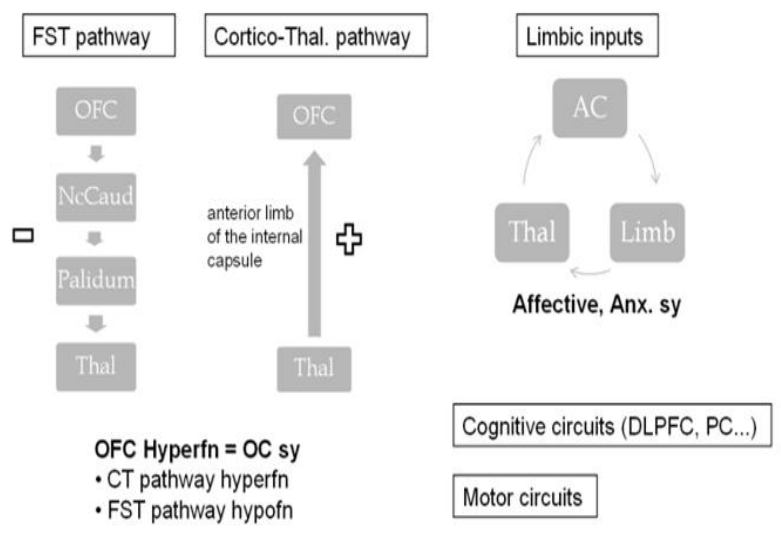

Figure 3. Neuronal circuits in OCD pathophysiology.

\section{Imaging and diagnosis in psychiatry}

Characteristically, imaging studies assess a group of subjects. However, the information value, as regards a single patient, is problematic. The reason is the heterogeneity of the groups of subjects as well as the statistical power of the tests. These difficulties in the assessment of individuals lead to a significant gap between what happens in the laboratory and clinical practice.

This distance can be overcome using modern techniques of analysis and classification of patterns (pattern recognition, detection) and mathematical techniques searching for typical features of the studied group/individual. Then by looking for these features in individual subjects it may be possible to classify them according to their presence/absence (one of the known applications is, for instance, recognition and identification of faces, recognition of fingerprints, etc.). These techniques can also be applied to brain images - in this way it is possible to try to recognize functions that the brain performed during the examination, but there is also the potential to classify subjects as patients or healthy individuals, etc. If we succeeded in verifying the applicability of such methods, it could bring imaging methods closer to clini- 
cal practice in psychiatry (diagnosis, prognosis, etc). On the basis of brain imaging, this would become possible. Existing experience has so far been encouraging; if information on the subject's clinical picture is used in addition to imaging information, classification accuracy can reach 96\% (Nenadic et al., 2010)! An even higher classification accuracy was achieved in a population with more pronounced morphological changes: classification accuracy of $98 \%$ has been reached in Alzheimer's dementia (Thomaz et al., 2007).

\section{Neurobiology and therapy targets}

Let this last example, of the application of imaging methods in psychiatry, represent imaging's contribution to the search for therapy targets - let us refer to the example of deep brain stimulation in obsessive-compulsive disorder (OCD). Positron emission tomography in OCD patients found increased fluoro-deoxy-glucose uptake at rest in the orbitofrontal cortex (OFC), in the anterior cingulum (AC), nucleus caudatus (NcCaud), and the thalamus (Thal); however, it also found it in the premotor, sensorimotor cortex, in the posterior cingulum, dorsolateral prefrontal cortex, the insula, the parietal and occipital cortex and the cerebellum (for review see (Menzies et al., 2008). Similar changes were found by an activation likelihood meta-analysis of fMRI studies which revealed changes in function in the OFC (BA 10, 47), AC (BA 32), the NcCaud, the putamen, the Thal, motor area (BA6), the insula, the hippocampus, the posterior cingulum (BA 30), the precuneus (BA7), the occipital cortex as well as the cerebellum (Menzies et al., 2008). Changes in these areas can be placed in the context of neuronal circuits (see Figure 3): the OFC, the NcCaud, the pallidum and the thalamus are connected by the inhibitory fronto-striato-thalamic pathway and the excitatory feedback is mediated by the corticothalamic pathway running through the anterior limb of the internal capsule. OFC hyperfunction is regarded as the basis of obsessive-compulsive symptomatics; it can be induced either by hyperfunction of the corticothalamic pathway or by hypofunction of the corticostriato-thalamic pathway. The anterior cingulum, the thalamus and the limbic areas are responsible for affective and anxiety symptoms (Kopell et al., 2004). Furthermore, cognitive circuits (the dorsolateral prefrontal cortex, the parietal cortex) and motor circuits are involved in the pathophysiology.

How can OFC hyperactivity be responsible for obsessive-compulsive symptomatics? The OFC encodes the representations of values (positive, negative; representations as well as operations). Characteristic cognitive styles have been described in OCD which represent a certain method of "evaluation" - inflated perception of responsibility and overestimation of danger. The treatment (SSRI and/or behavioral therapy) results in a decrease in hyperactivity in the $\mathrm{OFC}$, the $\mathrm{AC}$, the $\mathrm{NcCaud}$, and the Thal (Schwartz et al., 1996; Swedo et al., 1992). These areas also represent the target of neurosurgical interventions in patients resistant to standard treatment - cingulotomy (anterior), capsulotomy (anterior limb), subcaudate tractotomy, or limbic leucotomy (cingulotomy + subcaudate tractotomy). Although the neurosurgical approaches are effective in at least some resistant patients, ethical and practical reasons (irreversibility of the lesion) have led to the search for an alternative, which is currently available, in the form of chronic deep brain stimulation (DBS) of the area of the anterior limb of the internal capsule. About $60 \%$ of patients resistant to conventional treatment respond to this treatment (Greenberg et al., 2008). In this way, imaging methods interconnect psychopathology, pathophysiology and the targeting of modern therapeutic approaches. Similarly, imaging methods contribute to the search for treatment targets for DBS in the depressive disorder, transcranial magnetic stimulation in auditory hallucinations or negative symptoms in schizophrenia.

\section{CONCLUSION}

Imaging methods enable us to study the neurobiology of mental disorders - they have actually shown that mental disorders do have a neurobiology, that they are not only functional or psychogenic conditions. Imaging methods also contribute to the theoretical understanding of mental disease with cognitive neuroscience allowing us to gain insight into the mechanisms of symptom development. Imaging techniques, with the help of animal and histopathological studies, and in the context of clinical diagnosis, allow assessment of the neuropathology as well as the effect of treatment. Imaging methods may enable subject classification, recognize defined pathological conditions, which might be useful for diagnosis and differential diagnosis; such advancements would improve the relevance of imaging methods to clinical practice. Additionally, imaging methods contribute to the understanding of the mechanism of action of psychopharmaceuticals and allow us to search for the targets of biological treatment. They do not, however, enable access to the contents of the "psyche", i.e. we are not able to find out WHAT the person perceives, WHAT they are thinking about and WHAT they remember. The findings of imaging methods do show changes at a level below that of subjective experience, 
which are accessible through introspection or mediated through interviews. The relationships between the findings of imaging methods and the subjective level can be estimated only from information gained using parallel methods, "indirectly", and they are, to a varying extent, speculative. Notwithstanding, imaging methods, in the hands of a psychiatrist, represent an invaluable tool for studying mental disorders, with numerous clinical overlaps.

\section{ACKNOWLEDGEMENT}

This work was supported by a research grant of the Ministry of Health, Czech Republic No. NR9893-4.

\section{REFERENCES}

Abi-Dargham, A. (2003). Probing cortical dopamine function in schizophrenia: what can D1 receptors tell us? World Psychiatry, 2, 166-171.

Abi-Dargham, A., Gil, R., Krystal, J., Baldwin, R.M., Seibyl, J.P., Bowers, M., van Dyck, C.H., Charney, D.S., Innis, R.B., \& Laruelle, M. (1998). Increased striatal dopamine transmission in schizophrenia: Confirmation in a second cohort. American Journal of Psychiatry, 155, 761-767.

Abi-Dargham, A., Rodenhiser, J., Printz, D., Zea-Ponce, Y., Gil, R., Kegeles, L.S., Weiss, R., Cooper, T.B., Mann, J.J., Van Heertum, R.L., Gorman, J.M., \& Laruelle, M. (2000). Increased baseline occupancy of D-2 receptors by dopamine in schizophrenia. Proceedings of the National Academy of Sciences of the United States of America, 97, 8104-8109.

Agid, O., Mamo, D., Ginovart, N., Vitcu, I., Wilson, A.A., Zipursky, R.B., \& Kapur, S. (2007). Striatal vs extrastriatal dopamine D2 receptors in antipsychotic response--a doubleblind PET study in schizophrenia. Neuropsychopharmacology, 32, 1209-1215.

Angrist, B., Rotrosen, J., Gershon, S. (1980). Responses to apomorphine, amphetamine, and neuroleptics in schizophrenic subjects. Psychopharmacology, 67, 31-38.

Angrist, B., Sathananthan, G., Wilk, S., \& Gershon, S. (1974). Amphetamine psychosis- behavioral and biochemical aspects. Journal of Psychiatric Research 11, 13-23.

Bandettini, P.A. (2009). What's new in neuroimaging methods? Annals of the New York Academy of Sciences, 1156, 260-293.

Beahrs, J.O. (1986). Limits of scientific psychiatry. New York: Brunner/Mazel, Inc.

Berridge, K.C., \& Robinson, T.E. (1998). What is the role of dopamine in reward: hedonic impact, reward learning, or incentive salience? Brain Research Reviews, 28, 309-369.

Carlsson, A., \& Lindqvist, M. (1963). Effect of chlorpromazine or haloperidol on formation of 3-methoxytyramine and normetanephrine in mouse brain. Acta Pharmacologica et Toxicologica, 20, 140.

Dazzan, P., Morgan, K.D., Orr, K., Hutchinson, G., Chitnis, X., Suckling, J., Fearon, P., McGuire, P.K., Mallett, R.M., Jones, P.B., Leff, J., \& Murray, R.M., (2005). Different effects of typical and atypical antipsychotics on grey matter in first episode psychosis: the AESOP study. Neuropsychopharmacology, 30, 765-774.

Fenton, G.W. (1984). The electroencephalogram in psychiatry: clinical and research applications. Psychiatric Developments, 2, 53-75.

Garver, D.L., Holcomb, J.A., \& Christensen, J.D. (2005). Cerebral cortical gray expansion associated with two secondgeneration antipsychotics. Biological Psychiatry, 58, 62-66.

Greenberg, B.D., Gabriels, L.A., Malone, D.A., Jr., Rezai, A.R., Friehs, G.M., Okun, M.S., Shapira, N.A., Foote, K.D., Cosyns, P.R., Kubu, C.S., Malloy, P.F., Salloway, S.P., Giftakis, J.E., Rise, M.T., Machado, A.G., Baker, K.B., Stypulkowski, P.H., Goodman, W.K., Rasmussen, S.A., \& Nuttin, B.J. (2010). Deep brain stimulation of the ventral internal capsule/ventral striatum for obsessive-compulsive disorder: worldwide experience. Molecular Psychiatry, 15, 64-79.

Gur, R.E., Maany, V., Mozley, P.D., Swanson, C., Bilker, W., \& Gur, R.C. (1998). Subcortical MRI volumes in neurolepticnaive and treated patients with schizophrenia. American Journal of Psychiatry, 155, 1711-1717.

Hietala, J., Syvalahti, E., Vuorio, K., Rakkolainen, V., Bergman, J., Haaparanta, M., Solin, O., Kuoppamaki, M., Kirvela, O., Ruotsalainen, U., et al. (1995). Presynaptic dopamine function in striatum of neuroleptic-naive schizophrenic patients. Lancet, 346, 1130-1131.

Honea, R., Crow, T.J., Passingham, D., \& Mackay, C.E. (2005). Regional deficits in brain volume in schizophrenia: a meta-analysis of voxel-based morphometry studies. American Journal of Psychiatry, 162, 2233-2245.

Hurley, R.A., \& Taber, K.H. (2008). Windows to the brain: Insights from neuroimaging. Arlington: American Psychiatric Publishing, Inc.

Javitt, D.C. (2007). Glutamate and schizophrenia: phencyclidine, N-methyl-D-aspartate receptors, and dopamineglutamate interactions. International Review of Neurobiology, 78, 69-108.

Johnstone, E.C., Crow, T.J., Frith, C.D., Husband, J., \& Kreel, L. (1976). Cerebral ventricular size and cognitive impairment in chronic schizophrenia. Lancet, 2, 924-926.

Kalivas, P.W., \& Duffy, P. (1995). Selective activation of dopamine transmission in the shell of the nucleus-accumbens by stress. Brain Research, 675, 325-328.

Kapur, S. (2003). Psychosis as a state of aberrant salience: A framework linking biology, pheno-menology, and pharmacology in schizophrenia. American Journal of Psychiatry, 160, 13-23.

Karlsson, P., Farde, L., Halldin, C., \& Sedvall, G. (2002). PET study of $\mathrm{D}(1)$ dopamine receptor binding in neuroleptic-naive patients with schizophrenia. American Journal of Psychiatry, 159, 761-767.

Kasparek, T. (2009). Prefrontal Morphology, Neurobiology and Clinical Manifestation of Schizophrenia In: LoGrasso, L., Morretti, G. (Eds.), Prefrontal Cortex: Roles, Interventions and Traumas. Nova Science Publishers, Inc., New York, pp. $1-47$.

Kasparek, T., Kucerova, H., Prikryl, R., Ceskova, E., Mikl, M., \& Krupa, P. (2008). Morphology of fronto-temporal re- 
gions and word generation in first-episode schizophrenia. Activitas Nervosa Superior, 50, 88-90.

Kasparek, T., Prikryl, R., Schwarz, D., Tronerova, S., Ceskova, E., Mikl, M., \& Vanicek, J. (2009). Movement sequencing abilities and basal ganglia morphology in first-episode schizophrenia. World Journal of Biological Psychiatry, 10, 752762.

Kopell, B.H., Greenberg, B., \& Rezai, A.R. (2004). Deep brain stimulation for psychiatric disorders. Journal of Clinical Neurophysiology, 21, 51-67.

Lang, D.J., Kopala, L.C., Vandorpe, R.A., Rui, Q., Smith, G.N., Goghari, V.M., Lapointe, J.S., \& Honer, W.G. (2004). Reduced basal ganglia volumes after switching to olanzapine in chronically treated patients with schizophrenia. American Journal of Psychiatry, 161, 1829-1836.

Laruelle, M., Abi-Dargham, A., van Dyck, C., Gil, R., D'Souza, D.C., Krystal, J., Seibyl, J., Baldwin, R., \& Innis, R. (2000). Dopamine and serotonin transporters in patients with schizophrenia: An imaging study with [I-123]beta-CIT. Biological Psychiatry, 47, 371-379.

Laruelle, M., AbiDargham, A., vanDyck, C.H., Gil, R., Dsouza, C.D., Erdos, J., McCance, E., Rosenblatt, W., Fingado, C., Zoghbi, S.S., Baldwin, R.M., Seibyl, J.P., Krystal, J.H., Charney, D.S., \& Innis, R.B. (1996). Single photon emission computerized tomography imaging of amphetamine-induced dopamine release in drug-free schizophrenic subjects. Proceedings of the National Academy of Sciences of the United States of America, 93, 9235-9240.

Lennox, B.R. (2009). The clinical experience and potential of brain imaging in patients with mental illness. Frontiers in Human Neuroscience, 3, 46.

Lieberman, J.A., Tollefson, G.D., Charles, C., Zipursky, R., Sharma, T., Kahn, R.S., Keefe, R.S., Green, A.I., Gur, R.E., McEvoy, J., Perkins, D., Hamer, R.M., Gu, H., \& Tohen, M. (2005). Antipsychotic drug effects on brain morphology in first-episode psychosis. Archives of General Psychiatry, 62, 361-370.

Lindstrom, L.H., Gefvert, O., Hagberg, G., Lundberg, T., Bergstrom, M., Hartvig, P., \& Langstrom, B. (1999). Increased dopamine synthesis rate in medial prefrontal cortex and striatum in schizophrenia indicated by L-(beta-11C) DOPA and PET. Biological Psychiatry, 46, 681-688.

Menzies, L., Chamberlain, S.R., Laird, A.R., Thelen, S.M., Sahakian, B.J., Bullmore, E.T., 2008. Integrating evidence from neuroimaging and neuropsychological studies of obsessive-compulsive disorder: the orbitofronto-striatal model revisited. Neuroscience and Biobehavioral Reviews, 32, 525-549.

Molina, V., Reig, S., Sanz, J., Palomo, T., Benito, C., Sanchez, J., Sarramea, F., Pascau, J., \& Desco, M., (2005). Increase in gray matter and decrease in white matter volumes in the cortex during treatment with atypical neuroleptics in schizophrenia. Schizophrenia Research, 80, 61-71.

Narr, K.L., Bilder, R.M., Toga, A.W., Woods, R.P., Rex, D.E., Szeszko, P.R., Robinson, D., Sevy, S., Gunduz-Bruce, H., Wang, Y.P., DeLuca, H., \& Thompson, P.M. (2005). Mapping cortical thickness and gray matter concentration in first episode schizophrenia. Cerebral Cortex, 15, 708-719.
Nenadic, I., Sauer, H., \& Gaser, C. (2010). Distinct pattern of brain structural deficits in subsyndromes of schizophrenia delineated by psychopathology. Neuroimage, 49, 1153-1160. Nordstrom, A.L., Farde, L., Eriksson, L., \& Halldin, C. (1995.) No elevated D2 dopamine receptors in neurolepticnaive schizophrenic patients revealed by positron emission tomography and $[11 \mathrm{C}] \mathrm{N}$-methylspiperone. Psychiatry Research, 61, 67-83.

Reith, J., Benkelfat, C., Sherwin, A., Yasuhara, Y., Kuwabara, H., Andermann, F., Bachneff, S., Cumming, P., Diksic, M., Dyve, S.E., Etienne, P., Evans, A.C., Lal, S., Shevell, M., Savard, G., Wong, D.F., Chouinard, G., \& Gjedde, A. (1994). Elevated dopa decarboxylase activity in living brain of patients with psychosis. Proceedings of the National Academy of Sciences of the United States of America, 91, 11651-11654.

Rorden, C., \& Karnath, H.O. (2004). Using human brain lesions to infer function: a relic from a past era in the fMRI age? Nature Reviews Neuroscience, 5, 813-819.

Seeman, P., Lee, T., Chau-Wong, M., \& Wong, K. (1976). Antipsychotic drug doses and neuroleptic / dopamine receptors. Nature, 261, 717-719.

Scheepers, F.E., de Wied, C.C., Hulshoff Pol, H.E., van de Flier, W., van der Linden, J.A., \& Kahn, R.S. (2001). The effect of clozapine on caudate nucleus volume in schizophrenic patients previously treated with typical antipsychotics. Neuropsychopharmacology, 24, 47-54.

Schmitt, G.J., Meisenzahl, E.M., Frodl, T., La Fougere, C., Hahn, K., Moller, H.J., \& Dresel, S. (2005). The striatal dopamine transporter in first-episode, drug-naive schizophrenic patients: evaluation by the new SPECTligand[99mTc]TRODAT-1. Journal Psychopharmaco-logy, 19, 488-493.

Schwartz, J.M., Stoessel, P.W., Baxter, L.R., Jr., Martin, K.M., \& Phelps, M.E. (1996). Systematic changes in cerebral glucose metabolic rate after successful behavior modification treatment of obsessive-compulsive disorder. Archives of General Psychiatry, 53, 109-113.

Swedo, S.E., Pietrini, P., Leonard, H.L., Schapiro, M.B., Rettew, D.C., Goldberger, E.L., Rapoport, S.I., Rapoport, J.L., \& Grady, C.L. (1992). Cerebral glucose metabolism in childhood-onset obsessive-compulsive disorder. Revisualization during pharmacotherapy. Archives of General Psychiatry, 49, 690-694.

Takahata, R., \& Moghaddam, B. (2000). Target-specific glutamatergic regulation of dopamine neurons in the ventral tegmental area. Journal of Neurochemistry, 75, 1775-1778.

Thomaz, C.E., Duran, F.L., Busatto, G.F., Gillies, D.F., \& Rueckert, D. (2007). Multivariate Statistical Differences of MRI Samples of the Human Brain. Journal of Mathematical Imaging and Vision, 29, 95-106.

Thompson, P.M., Bartzokis, G., Hayashi, K.M., Klunder, A.D., Lu, P.H., Edwards, N., Hong, M.S., Yu, M., Geaga, J.A., Toga, A.W., Charles, C., Perkins, D.O., McEvoy, J., Hamer, R.M., Tohen, M., Tollefson, G.D., \& Lieberman, J.A. (2009). Time-Lapse Mapping of Cortical Changes in Schizophrenia with Different Treatments. Cerebral Cortex, 19, 1107-23. 
Tune, L.E., Wong, D.F., Pearlson, G., Strauss, M., Young, T., Shaya, E.K., Dannals, R.F., Wilson, A.A., Ravert, H.T., Sapp, J., et al. (1993). Dopamine D2 receptor density estimates in schizophrenia: a positron emission tomography study with 11C-N-methylspiperone. Psychiatry Research, 49, 219-237.

Vallarta-Ast, N., Krueger, D., \& Binkley, N., 2002. Densitometric diagnosis of osteoporosis in men: effect of measurement site and normative database. Journal of Clinical Densitometry, 5, 383-389.

Wong, D.F., Wagner, H.N., Jr., Tune, L.E., Dannals, R.F., Pearlson, G.D., Links, J.M., Tamminga, C.A., Broussolle, E.P., Ravert, H.T., Wilson, A.A., Toung, J.K., Malat, J., Williams, J.A., O'Tuama, L.A., Snyder, S.H., Kuhar, M.J., \& Gjedde, A. (1986). Positron emission tomography reveals elevated D2 dopamine receptors in drug-naive schizophrenics. Science, 234, 1558-1563.

Zakzanis, K.K., \& Hansen, K.T. (1998). Dopamine D2 densities and the schizophrenic brain. Schizophrenia Research, 32, 201-206. 